\title{
Spatialization of Time and Temporalization of Space: A Critical Discourse on McTaggart's Theory of the Inexistence of Time
}

\author{
*Taye Richard Oyelakin \\ http://dx.doi.org/10.4314/ujah.v15i1.8
}

\begin{abstract}
This paper critically structures the debate that arose on McTaggart thesis of the inexistence of time. The debate shows that the question about what time is, is a very complex one, which has, at present, defiled a generally acceptable answer. Of course, it familiarly and obviously looks to us as there is time, but upon further probe, it is found out we no longer know that which we think we were initially sure of. In other words, we believe each event happens in time, but of what time consists, its properties and nature, the paper shows that we do not have any sufficient ground as a support for our claim. Furthermore, the paper shows that for any meaningful and clearer progress to be made on the question of the nature of time, some other concepts such as space, causation, present, past, future, earlier than, later than, etc, have to be sufficiently explained. All of these raise the problem of the relationship between our language (mathematical, logical, geometrical and grammatical) and the question of time on one hand and the relationship between our language and the supposed mental phenomena, on the other. It is shown that there is the possibility of the fact that the problem is that of a certain technical or conceptual deficiency in our language.
\end{abstract}


Key Words: Spatialisation, Temporalisation, Space, Aseries, B-series.

\section{Introduction}

The idea of time has become a recurrent philosophical debate among scholars without any generally acceptable position. Events in the world are observed to be changing and this made some people to take time to be equivalent to change, but this was discountenanced by some scholars who argue that every alteration occurs in time. But the pertinent and challenging question is; what is time? Is time real or is it just a conceptual acronym to designate the non-existent? It is the uncertainty in the quest about time that prompted some other philosophers like McTaggart to strongly argue that there is no time. But again, is there no time, is it the case that what we use to measure speed and event in the world is a mere delusion of man's understanding? This is the question to which other philosophers attempt to respond. Did they succeed in their attempt to find an answer to this question?

It is the controversy over the concept 'time' that the paper intends to dwell in. The paper will examine whether time has only a conceptual content, subjective reference, or psychological existence without any real existence in the external world. Or whether upon all what has been said, there is something in the world which can be explained as depicting time. In other words, the paper will research whether time exist, in the real sense of existence, in the external world. Attempt would be made to examine some literatures where people responded to McTaggart claim about the 
unreality of 'time' and we do hope that these would be able to guide us in the discussion.

\section{McTaggart Concept of Time}

Most philosophical discourse about the problem or the puzzle of time has been in response to McTaggart's (1993) well-known paper on the unreality of time ${ }^{1}$. According to him, there are positions which distinguish time. First, that which orders events in terms of past, present and future which he termed as 'A-series' and second; that which orders events in terms of 'earlier than some', 'later than some', which he identified as 'Bseries'. However, for time to be real, change must also be real, and real change is possible only within a real Aseries which involves past, present and future, hence, Aseries is more fundamental to time than B-series. He argued for the unreality of A-series and subsequently of time. According to him, the past, present, and future are incompatible determinations of an event. That is, if any event is present, it cannot be past or future at the same time. The same thing occurs with past or future events. This implies that A-series are inherently contradictory. Nonetheless, every event has them all, if any event is past, it had been present and future. He held that these two statements are simply inconsistent and therefore Aseries and consequently change and time, cannot exist.

In McTaggart's view which regards A-series as real; that event ' $E$ is present' is a fact in the world (reality), and so 
are ' $\mathrm{E}$ is past' and ' $\mathrm{E}$ is future', but these are incompatible, yet, the 'moving now' demands all of them to be, therefore, time is unreal. Series of puzzling things are observed to happen regarding events and movements. Things or events are observed to sometimes lie in the distant future and gradually coming towards the immediate future then to the present when we observe such event to be happening at the very moment such utterance is made. Then, with a sufficient and regular speed rate, that event instantly continues to sink into the past. The earliest part of such event is seen to first of all disappear into the past before the later part. And the whole event eventually tumbles into the immediate past and gradually with a regular consistency, it continues to move into the remote past. For instance, a journey to Abuja first of all lies in the remote future, perhaps, in the next five years. But gradually, those five years continues to reduce and at a time, it will remain a year, then to six months, then one month and later to days or hours which are seen as the immediate future event. At last, the day will come and the first phase of the journey starts, perhaps, with preparations. Then, immediately the journey starts, the preparation aspect that precedes the journey will slip into the past. Eventually, as the activities in the journey continue to unfold, the preceding parts continue to roll into the past. 


\section{Broad's Dydic and Triadic Spatio -Temporal Relations}

For C.D. Broad ${ }^{2}$ however, facts such as the above are what constitute what is called temporal characteristics, and these facts are seen as the very essence of time. He argued that there are two aspects to which time can be classified. These are duration and temporal relation. The close interconnection of these two aspects engenders the close analogy between time and space. Given this, it will become impossible to explicate time in terms of duration and temporal relations without having to include the characteristics of space. But for him, even though time and space could be understood to share some certain properties, it is not the case that in all the cases what is true of time is true of space. For him, there are certain relations, which are true of time but not true of space. One of such relations is that of triadic relation of between. Though, the relation of between occur both in time and space, but there is a profound difference. For instance, for spatial relation, we can say that Ikire is in between Ibadan and Ile-Ife, and for temporal relation, we can say that my writing this paper is between the experiences of sleeping. There, for Broad, lies a profound difference between the spatial and temporal relation.

The above example of temporal relation of betweeness can be analysed into a dyadic relational couple. For instance, it can be argued that the experience of eating 
my dinner preceded my writing this paper and writing this paper preceded my sleeping. The argument is that such a translation of a triadic relational fact, done with temporal relation of betweeness is not possible with spatial relation of betweeness. In fact, when one considers the relation of south of or north of in spatial relation, we have: Ibadan is south of Ogbomosho, and Ogbomosho is south of Ilorin. Comparing this with the temporal relational fact, one discovers another difference. While temporal relational fact does not require any external references, spatial relational fact does. The relation south of involves a reference to some third term besides those mentioned. Those third terms are either the sun or the compass needle. But in the case of the temporal relation of earlier than which is a genuinely dyadic relation that directly relates two experiences of the same person, there is no reference to some third term. The point above bothers on the fact that this dyadic relation is intrinsic to the series of the temporal experiences which constitutes a person's mental history. But this is without any reference to any third term. The spatial relation series does not contain this intrinsic property of the dyadic relation except with a reference to some external third term. The intrinsic relational series in the temporal relation is contained in two intrinsically opposite directions, earlier-to-later and later-to-earlier. But, there is no such intrinsic direction in spatial relational series without reference to external motion along the line, therefore to time, by reference to right or left hand of an external observer. 
In spite of these obvious differences in spatial and temporal relations, Broad argues that there are instances when spatial relations presuppose temporal relations. For example, the ideas of shape and size are spatial in nature because they are ascribed to particulars. But it should be understood that these particulars persist through periods of time and also have histories of longer or shorter duration. Besides, one and the same thing can have different determinate shapes and sizes at different time in its history. Then, we have to divide its history into short successive phases during each of which its size and shape are sensibly constant. Or if the thing is very rigid and remaining unchanged, in shape and size over a long period of time, then instead of referring to a particular moment, we refer to a regular and constant shape and size which it sustains at every moment throughout such long period. In one word, the argument is that the notion of size and shape as applied to bodies cannot be successfully explained without an explicit reference to temporal characteristics/relations. Broad's argument on the transitory nature of temporal fact bothers on the characteristics of pastness, presentness, and futurity and that every event is continually changing in respect of these characteristics. In the first instance, he identified the determinacy of these characteristics with our use of languages, especially the use of tense or a temporal copula with some certain temporal adverbs. Then for instance, it may be said that (a) I had my dinner lately, I am writing now, I shall be sleeping soon. (b) The other way is through a single uniform copula and temporal adjectives plus some adverbs that take three different forms. Thus, it may be said that eating my dinner is just 
past, my writing is present, sleeping is slightly future and so on. Though these forms of expressions are not naturally common but, according to him, they are intelligible.

The major point we can make out of this is that what is called the presentness is highly transitory. This is because there is no particular time to point to as the present. As soon as it becomes the present from the future, also it instantly moves into the past even before we are able to point to it. But pastness and futurity might be seen as the two extremes of temporal relation, which can be pointed to in time. Presentnesss could then be seen as the connection between the future and the past. You can have immediate past or future, though both are also in continuous movement of change. The above goes with Broad's argument that these temporal characteristics are relative to the speaker. This is because it highly depends on the temporal state of the speaker and the experience he is having at a particular moment. But, it could be instantly understood here, I think, that since what is called the present is continuously transitory and never static, then it might be difficult to refer to a given period of time as the present. However, this point might be difficult to hold in view of our linguistic scheme. There is the principle of minimum mutilation to our scientifique-linguistic system.How, for instance, can one argue that there is no present? Is the event of my sitting in front of this system and typing now not present? What other means to determine the present than the event happening at the time the actor is expressing himself? But, I think every event is supposed to be 
capable of being divided into the three temporal divisions. These are; the past, the present and the future. In that case the event of my sitting in front of this computer now can not wholly be said to be present. This is because it started in the past, it is happening now and it is going to end in the future.

One thing is clear however in the division of the event that is happening now; there is the present aspect of it. If we are able to show it, we would have been able to show contrary to Broad that there is presentness in the temporal series or relations. An aspect of the typing is past. And certainly an aspect is now present. And an aspect of it is also in the future. It is agreed that all the aspects or series are in constant change. It must also be agreed that at least the pressing of the last key on the keyboard, must occur in the present before it becomes past. But we may be challenged to prove how such presentness might be determined, because it may also be argued that the pressing of my last key is in itself an event, and it must also be divided into the three temporal relations of pastness, presentness and futurity.

To this, for our clarification, we want to use, as our example, the man-made clock. Perhaps, presentness can easily be analysed with this. When it is 50 'clock, we say that at present it is 5 o'clock, and when it is quarter past, we confirm it as what is present. But we may still be asked; are these events present? It may be argued that when we say it is 5 o'clock, the second would have changed and then it is no more present. However, it is possible at least to conceive of an event when the hour, 
the minute and the second will be exactly 5 o'clock. Then do not we say that such event is present? Our opponent may still insist that such event is not present because at such a time, the milli-second can not, at that very instance, be in the present, because by the time we say that it is at present 5 o'clock, the milli-seconds would have quickly changed, making the event to have become past. But such progress will certainly lead to an infinite regress. This is because appeal would be made to further divisions of seconds. The point is that at a particular moment in the constantly changing series, there is the presentness marker.

At this point it would be certain that time is infinitely divisible. And if time is infinitely divisible, it may appear difficult to determine presentness. And if there is no present then we can not be so certain that there is the past and the future. And if the existence of these is uncertain then how can we be certain of the existence of time. It might be safe to conclude with McTggart that certainly there no time. This conclusion raises a big question against our conventional belief about time. Is there no time? For a possible answer we have to look elsewhere in Findlay's conception of time.

\section{Findlay's Concept of Time and Linguistic Usage}

The major attempt and aim of Findlay's ${ }^{3}$ paper is not to offer a solution to the problem of time but to show that the difficulties which worry us have their origin in our 
ways of thinking and talking. For him, in our ordinary life, we do not see any difficulty in comprehending and using time. This is because we mostly and simply use temporal statement such as 'this lasted longer than that, this took place at the same time as that or this has just happened or that will happen soon'. However these temporal statements create problem for some people which make them claim that time is paradoxical, contradictory, or mysterious. This has led to some cogent questions on the concept of time and its nature. For Findlay, it is odd for people who have spent all their time in temporal process to profess a difficulty about that time as if they are "visitors from eternity". The cause of such a difficulty is what the paper aims at clarifying. To a question: how is it possible for that which is the case to ever cease to be the case?, he provided an ostensive answer but considered it unsatisfactory because, it is like an appeal to experience to which the questioner also has access to and observe. But for him, this is one of the easiest ways to settle the question. Findlay argued that most puzzles are not really problem but our lack of linguistic clarity and harmony which make our understanding of such common issue unclear and unsatisfactory. The best way to deal with such a problem is to understand and clarify the cause(s) of such puzzles.

Findlay, however, identified the problem or puzzles of time as an important philosophical point of interest. He first of all identified the problem of time with our linguistic usage. For him, linguistic terms or propositions are used in variety of ways depending on the persuasion of our environment and the need of the 
time. For instance, a person may be so persuaded to use a certain linguistic locution in a very wider and even novel sense with the belief that such certain linguistic statement may be used to apply to or to cover a wide range of directions or everything without any noticeable and clear boundary. Linguistic statements may also be employed in a very narrow sense, obeying the laws of strictness and consistency in which case such speech or statement may be used that they apply to nothing. An example of a widely use of linguistic terms is seen in Leibniz's monadology (monads) which are used to explain the knowledge of everything. Both instances of linguistic usage are the causes of problem of linguistic understanding which lead to paradoxes or contradictoriness.

In relation to time, he argued that it is possible to use temporal term 'present' in stricter manner such that it applies to nothing. Or at best it may apply to a novel or an artificial thing. Ordinarily, we use the present tense with the temporal adverb "now", including other temporal terms denoting imperfect past and imperfect future tenses and words such as "then", "at that time", and so on. Examples of events that depict presentness and last a considerable time are; "Obasanjo is ruling now" or "The national Anthem is being sung". In such a wider sense, we use present tense to include events which started happening in the past but is in a continuous series till the present. This is because of our belief that a whole cannot be happening now without part happening at the same now.But when present is used in very strict and narrow sense, it may be difficult 
to agree that any event which takes a certain period of time to happen does so at the present time. The strict speaker, Findlay argued, will identify the temporal present only in happening which was so short that it took no time at all. In that wise, strictly, any event that takes time can not be said to happen at present. This means that present event cannot be temporal, since any event that takes time must have had part of its time in the past and some in the future. This therefore implies that no event happens in the present or rather that any event tagged with presentness must be such that it takes no time at all. For him, this is a wrong application of "present", which is meant for a fairly long duration, to a one with no duration or a short one. Then the result is turning a serviceable and meaningful way of talking to its opposite. Ordinarily, all events take time but logically or mathematically, timeless event may be proved. However, referring to timeless event as "present" might affect our speech habit since we may refer to them as those timely ones or as happenings we could point to. This tends to raise many confusing and unanswerable questions.

Now, Findlay argues that the problem with the concept of time is in the way we use our language, i.e. that we use our language in both narrow and broad senses when we refer to the concept of time. And since Findlay's identification of two ways by which we use our language in relation to time could not be said to have provided an answer to our question of time, then we think that the solution that Findlay might want to proffer is that we can use language in a mid- way between the narrow sense 
and the wide sense so as to solve the puzzle he identified with time. However, our problem here is about how we are to get the mid-way between the narrow and the wide sense, and even supposing that we are able to find a midway between the narrow and the wider usages of our language, the question is whether such mid-way use of our language will be able to solve our problem. In view of this one may think that the problem is not with the concept itself but with our use of language. Then, one may think the solution will be to probably re-analyze or rephrase the whole system of our language including concepts, in such a way that we will use the concept time not as an abstract term, as it has been used earlier in our language, but in relation to particulars in our empirical world. So that when we use the concept time, we do not mean more than the relations of changes among particular objects or events at some certain periods. This may demand that we delimit our reasoning about time as an abstract term so that we will not be led into antinomies.

\section{Findlay's Response to Augustine's Objections on Time} Findlay then responds to three problems raised by Augustine $^{4}$ about happening which is timeless as being referred to only as present. The first problem is that events with zero duration will just be nothing. And if the duration of an event were reduced to zero then it is impossible for something to come out of nothing. He argued that the Augustinian argument confuses tangible 
object like house and the connection with its parts with the abstract entity of time and event. It is unreasonable, for instance, to think of attempt to amass wealth from a zero contribution. This is not true of abstract event and time duration. For concerning time and happening, it depends on how we want to talk since we are free in that wise. We may claim that events which take time are made up of events which take no time.

Second, Augustine argues that happenings which take time are in separate stages. Then, it is difficult to say of event which has scattered stages to amount to anything or form a whole. Findlay argued that there is a difference between tangible entities such as houses, mountains, and so on and events, and time. While we may say that it is impossible to have a house with scattered parts, it is impossible to say of events that take time that its parts are present together. This is because events happening in time are different from houses or others. The parts in the houses co-exist together while the parts in events are said to be successive to each other.

Third, Augustine argued that an event that occurs in time includes some of its parts either in the past or future. Then how could such an event be measured? How do we measure it and what do we measure? Even the part present is in rapid change then he concluded that attempting to measure such is a futile one. Findlay objected that there is a considerable difference in a coexistence whole and a successive whole. Successive whole might have certain part in either the future or the past. But, to take care of the nothingness of the past, he claimed that even though there are some events which 
occur with succession in the present and are measured as a single whole, we may equally measure long event by going into their history. This makes him claim that the past may be said to subsist or exist since without claiming this, we may be precluded from extending our findings to the past as the nothingness of bachelor's childlessness prevented further findings. But in the case of past events, there are various ways of establishing what had happened. He also argued that we can not revisit or resist the past like we can revisit Abuja or reviving a drowning man.

However, Findlay argued that we might deny the foundation upon which Augustine's problems stand. And that will mean that we can deny that there are events which happen without time. For instance, when we talk of parts in ordinary utterance, we do not use past and present as terms there. Also, there are events which happen as a complete whole and this is also in agreement with our ordinary usage. The idea of part by part unfolding of event has also been questioned as that which does not correspond with nature of human brain because there is a limit to which human judgments and understanding can follow infinite division of events. And he further argued that if the problem of zeno's paradox is brought under this consideration, it will be certain that no motion or change in time will be possible for it would be impossible to cover the infinity of the division of time. However, even if any thing stands motionless, he argued that such a thing is still an event in time. So in both cases, events in time cannot be totally denied. 


\section{Nelson Goodman's Idea of Time}

Nelson Goodman ${ }^{5}$ approached the problem of time and space from a linguistic point of view. For him, in our ordinary utterances we indicate time of event by the use of some words such as now, yesterday, next week, past, later, or by the use of the tense of verb. We use these time indicators to express a statement indicating a distinct time of event as opposed to general and timeless expressions. For instance, Obasanjo is in Abuja now is a time specifying statement different from $\mathrm{x}$ is yellow which is a timeless statement. He identified the commonest indicators and temporal indicators. Examples of personal indicators are, 'I', or 'me' which refers to the speaker and certain others in that circumstantial context. 'You' is an indicator referring to the listener. 'I love Nigeria', 'I' is a personal indicator.

For spatial indicator, there is 'here' or 'yonder' and so on. 'Here' as a spatial indicator names a particular region or place where the indicator is made while 'yonder' refers to a distant region from where the utterance is made. Besides, what a spatial indicator names depends partly upon its context, including an ostensive description that is, by pointing.But the primary concern of Goodman in this context is the temporal indicator. One of the temporal indicators is 'now'. For him, this temporal indicator is just like the spatial 
indicator 'here'. 'Now' names a period in which it lies. This period could range from a moment to an era. 'Yesterday' or 'soon' is some other temporal indicator which names a period earlier or later than itself. Nonetheless, Goodman places a very important attention on these set of temporal indicators: past, present, and future, simply because they are "frequently abused in theoretical discourse" function like most 'now'; they name the period they lie in and many other varying periods. The 'past' often names a time preceding now or earlier than now. While 'future' names all the time following now (the period in which the utterance is made)

Goodman argued that a given period which is 'past' overlaps and it includes or is included in the period named by any other past. What I understand by this saying is that since time is continuous and events overlap, then, there cannot be a certain distinct event unconnected with any other event in the past. This connection among events created an illusory problem, which according to Goodman, metaphysicians have capitalized on to solve. The illusion is the belief or claim that 'what' is once past is always thereafter past (and that what is future was always therefore future) and which led to treating the past, the future and even the present as if all named the same thing. For him,

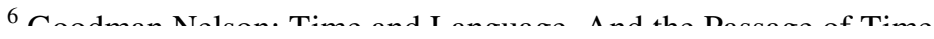


Also, verbs in some certain sentences may perform the function of a temporal indicator. Example, Jingo stood up to speak. This utterance does not only tell us what is done but also when, that is, earlier than the period of the utterance of the statement. Therefore, a verb in the present tense normally indicates a period within which the utterance is made while a futuristic verb tense indicate a period after its own production. However, carefulness is needed where more than one verb and temporal indicator are used. For instance, 'Randy had been running'. This, linguistically, means that the action of 'running' occurred prior to a certain moment which is in turn prior to the period of utterance. To buttress his argument, on the 'verb' used as temporal indicator, the sentences 'World War II' was present or 'World War II is past' displays two sets of temporal indicator verbs which are never affected by the 'present' in those sentences. And where these verbs appear 'is past' or 'is future' they function equally as 'was' or 'will be'. In most formal discourse, however, most verbs are not actually functioning as temporal indicator. This is even common with generalizations such as 'all men have spines'. This does not denote reference to men in the time present but also past and future.Goodman also argued that at a certain context, some replicas of temporal indicator are not eventually temporal indicator. For instance, in the sentence "we can know, at a given time, only what is past at that time or present at that time, not what is future at that time". For him, the 'past', 
'present' and 'future' in the above statement name no times. Instead 'is past', 'is present' or 'is future' are all tenseless two place predicates 'is earlier than' 'is at', and 'is later than'. But he argued that both tensed and tenseless statements have truth values and, besides, both are events in time. In the passage of time, Goodman's major concern is to attempt to interpret the statement that deals with the temporal flow of events. For instance, events are observed to be passing from the future to the present and finally to the past. Things are also steadily growing older and changing in time. For him, we only observe moments and periods in time progressing or moving from future towards the past but time itself does not move or shift its position. It is static in the temporal series.For instance, a certain moment in time is future and later that moment became present and still later it became past. All these occurred in time itself but time itself does not change. For him, the location or the colour or the shape of a thing may change but not its time, that is, moments and periods are observed to change only in time, but time itself does not and cannot change. Things only change in time and not time changing in things.

\section{Quine's Temporal Neutrality}

Quine also attributed the majority of problem with the concept time with our ordinary use of language. For instance, grammar displays relations of date as it does not do to relation of position, weight, and colour. This bias of language towards time is shown where every verb used in a sentence must show their tense, that is, relationship between the subject and time of the action. 
time, we must drop this 1dea of 'tense distinctions'. Quine argued that like it is done in mathematics and other theoretical branches of science, a present tense of the verb may be treated as if it is temporally neutral or as being timeless always. This, for him, will free us to omit temporal information or as it pleases, handle it like spatial information. His argument is that if time is treated as equal with space, then all the temporal indicators in the grammar aspect of language (verbs and tense) will be rephrased such as they will be in the timeless present, where words like 'then' or 'now' would then be introduced to take over the time indication of those verbs and tenses. Those words however will just refer to some implicit in the circumstance of those utterances. For instance, "I telephoned him but he was sleeping" will become "I telephone him then but he is sleeping then",

Although, he acknowledged the tendency for such a rephrasing to affect the use of or to distort our language, such effect is not a strange one. It is always done in natural science. Treating time at par with space. Then he argued that treating time at par with space will achieve some great things. Applying this to the problem raised by Heraclitus, for him, the moment temporal extent of the river is put at par with the spatial extent of the river, there will no more be the difficulty of stepping into or bathing in the same river twice and also that the river's change of substance at a given place from time to time comes to be

${ }^{7}$ Quine W.V. (1964) Time. In J.J.C.Smart (ed) Problems of Space and Time New York· Macmillan Publishino Co INC n 370-374 
seen as quite on par with the river's change of substance at a given time from place to place. Besides, treating time as space-like, also has dealt with the problem of personal identity. For Quine, this helps one appreciate that there is no reason why the first and fifth or following decades of one's life should not count as parts of the same man, however dissimilar.

Concerning Zeno's argument against motion, Zeno's paradox according to him becomes less difficult when time is seen as space- like. For him, Zeno's argument was based on the infinity division of space but he argued that just as it is for space, it is also for time. The space finite distance was divided according to Zeno in infinitely many parts and he argued that that infinite time must be consumed in traversing them all. But for Quine, it is also that infinitely many periods of time can just as well add up to a finite period as a finite distance can be divided into infinitely many component distances. The major argument here is that given Zeno's paradox, it becomes clearer that time should be treated space-like to provide some answers to some problems. The analogy between space and time which is simply termed as spatialisation of time or temporalisation of space is the major attempt of Richard Taylor. His focus is to show that there is no difference between spatial and temporal relations as believed by medieval philosophers. For him, those relations are radically alike. According to Taylor, terms ordinarily used in temporal relations have spatial counterparts and vice versa. 


\section{Taylor's Spatialisation of Time and Temporalisation of Space}

The main argument espoused by Richard Taylor above I think, is that for a temporal proposition to be necessarily and obviously true, it must be spatially true. In that wise, any temporal proposition which is not spatially true is not temporally true either. The same thing applies to spatial propositions. And if this proposition is understood, it will be clear that Taylor argued that any term that truly and correctly applies to time also truly and correctly applies to space. In fact, he referred to Nelson Goodman's work where temporal notion is explained through spatial notion. But I also think that this position is akin to Quine's position where he treated time as space-like only that Taylor did not argue in translating temporal propositions into timeless one or preferably, he did not sound like it. However, he also believed that temporal propositions can be reformulated in terms of spatial relations. For instance, the notion like distance, extension, length, parts, and so on are all true of both temporal and spatial contexts even though it is easily overlooked. According to Taylor, concepts like direction and physical objects involve both space and time. For instance, there are types of directions such as like from past to future or vice versa or from east to west. For him, none of these types of direction is more genuine than the others. Physical objects are true of temporal and spatial contexts since such objects have both kinds of extension and both kinds of parts. 
To emphasize Taylor's point, he identified some series of objections which he replied to in order to canvass his major claim that whatever is true of time is also true of space and whatever is false of space is also false of time. For instance he argued that as it is possible for an object to occupy a place in two different times, it is also very possible under clear consideration that an object may occupy two places at a single time. Some other argument of his are all tailored to achieve his set purpose only that he is a step away from, although implied by inference, saying that time and space are one and the same thing since all his arguments, critically examined, claimed a kind of identity between spatial and temporal propositions. This is clear from the principle of the identity of the indiscernible. This is because whatever is true of time is true of space and vice versa. However, in my view, much as Taylor has tried to persuasively carry his arguments across to achieve his aim, he appeared to have certainly begged the very point at issue. What he was occupied with is to argue that temporal propositions share in the same property with spatial propositions. He presupposed that the actual meaning of the concept time is settled. No wonder, he continued to use the concept time and temporal without any second thought.But as it could be evident from Taylor's works, it is not clear what he is equating with space because what we are exactly after is what he is using to discuss his major arguments. I expected that the first approach to his discussion should be to present his own working definition of time so that whenever he used time in his argument as he did, it would be clear what he meant. However, this he did not do and this made his paper very 
what is to be defined to define or discuss any other argument or discourse. The point I made is evident throughout his seven drawn up arguments to which he replied in order to drive home his position:

Hendel misunderstood Hume's argument on the idea of space and time. He argue that since; In general Hume's thesis was that the important ideas or belief naturally used by man in his daily life and reasoning were all functions of imagination, '... The characteristic phenomena of the human understanding were explained by reference to the associative principles of the imagination', then he argued that the idea of space and time has its source in the imagination, "analogous to that of cause and effect ...

However, William T. Parry, straightened up Hendel when he argued that Hendel completely misunderstood Hume. For Parry, all Hume meant was that if it had not been the imagination, it would not have been possible to "believe in the independent existence of objects of our senses, nor in the veracity of our memory- images..." Parry then argued that the relation of space and time are presented to the senses just the same way the object(s) which engage in such a relation is/are also so presented. This means there is no action of the imagination in this

\footnotetext{
${ }^{8}$ Hendel Charles Williams: Studies in the Philosophy of David Hume (Indianapolis, Ind., Bobbs-Merrill, 1963)
} 
process. Also, Parry argued that the fact that spatiotemporal relation is a complex relation does not presuppose that Hume appealed to imagination for its explanation. According to him "Hume never intimates that all complex ideas are formed by imagination".

Immanuel Kant ${ }^{9}$ (Kant Inaugural Dissertation, Ed, John Handyside), saw the issue at stake from a completely opposite point of view. He argued that time is not objective and not real. It is not something that resides in the external world as empirical objects, as claimed by Parry. For Kant,

Thus the notion of time (regarded as acquired through experience) is very badly defined in terms of the series existing after one another. For what the word after may signify, I know only by means of an antecedently formed concept of time. Things are one after another when they exist at different times, just as things are simultaneous when they exist at the same time (Handyside 1929).

Moreover, to drive this point home, he argued, "but as for the fact that we cannot estimate quantity of time save on the concrete, namely, either by motion or by the series of (our) thoughts, this is because the concept of time rests only on an internal law of the mind" (Handyside 1929).

9 John Handyside: Kant Inaugural Dissertation and Early Writings on Snace. (Chicago: Onen Court Pub.. 1929) 
substance, accident, or any relation, whether simultaneity, contiguity or succession, it will not be difficult to understand Kant that his concept of time is not objective but purely subjective which is a product of imagination. An objection to Kant, that time arises out of change, will not hold water simply because he had argued that it impossible to make such a claim, since no change could be conceived except as occurring in time. Meaning that it cannot be claimed that time arises from change but the other way round.

Leibniz correspondence with Dr. Clarke in his later years opened him up to the problem of space and time and this became the most significant part of his philosophy. Space and time are ideals which belong to world of appearance but are not real in themselves; they are neither appearances nor objects of perception but they belong to the order of perceptions. Space is the order of co-existence and time is the order of succession. Space and time are formal and not material entities and these formal entities are either absolute or relative. It is absolute if the materialist view of substance and cause is accepted and relative if it is rejected in favour of idealism $^{10}$.

Contrary to Newton, Leibniz rejected the absoluteness of space and time and denied their necessity as the framework of the universe. He also denied Newton's metaphysical theory of substantive units of force in

\footnotetext{
${ }^{10}$ Carr Herbert Wilson. (1920). Leibniz (New York, Dover Duhlination Ins 1000) nor 152,151
} 
reducing matter to phenomenon; instead he reduced space and time to forms of order in phenomena. In Leibniz own words, the theory of space and time is as follows;

I hold space and also time, to be something purely relative. Space is an order of co-existence as time is an order of successions. Space denotes in terms of possibility an order of things which in so far as they exist together exist at the same time, whatever is their several ways of existing. Whenever we see various things together we are conscious of this order between things themselves. ${ }^{11}$

Space and time then are things in themselves not properties of things; they are order of things.

Leibniz account of how we form the notion of space and time is such that when we perceive things, we think of them as co-existing in orderly manner with a simple relation between them which we call situation or distance. When the order of these perceived things change and it is such that the same thing which co-exist in one moment also co-exist in a later moment but with a change in their order, we say that they have changed places. But when there is a complete change in the relations of situations to one another of the things which continue from moment to moment we can say they have changed their spaces. This leads to his definition of 'a

${ }^{11}$ Ibid 
place' and finally the collection of simultaneous places as 'space'. This may lead to the notion of space as something absolutely in itself, something within which movements occur but Leibniz held that there is no necessity for an absolute reality outside and independent of the things which are the relation of situation to one another.

Broad has this to say about Leibniz position on time and space;

We may say that Leibniz regards space as a logical construction out of places, and he regards a place as a logical construction out of facts about the spatial relations of bodies. And he holds that the notion of absolute space and absolute places is a fallacy of misplaced concreteness $^{12}$.

In his letter to Clarke Leibniz rejected the idea of absolute theory which locate the world in space or in time, that is, the idea that space is logically prior to matter and that time is logically prior to events and processes. When we define space and time either negatively as void and lapse or positively as extension and duration, they can not be independent of things and are neither themselves things nor detachable adjectives of things hence not absolute but relative in that they represent the order of arrangement of things among

${ }^{12}$ Broad C. D.: Leibniz: An Introduction, Ed, C. Lewy (New York, Cambridge University Press, 1975) pg 59 
themselves. In Leibniz relational theory, there is no actual space or time existing prior to the creation of things and event. God creates space in and through creating bodies and arranging them spatially in relations to each other. His rejection of the absoluteness of time and space is on the bases of the fact that it would conflict with the principle of sufficient reasoning which govern all reasoning in regard to matters of facts; or that it will render it worthless. It is however remarkable that while Leibniz makes space and time relative; he does not make them subjective. They are the product of the cocoordinating activity of the mind, but they characterize nature, the objective world of Physics. In effect, he offers the metaphysical background of the modern principle of relativity, the autonomy of individual standpoint in the observation of nature ${ }^{13}$.

\section{Conclusion}

The paper sketched the debate that arose on McTaggart thesis of the inexistence of time. The debate, as presented in the paper, has shown that the question about what time is, is a very complex one, which has, at present, defiled a generally acceptable answer. Of course, it looks obviously to us as there is time, but upon further probe, we no longer know that which we were initially sure of. In other words, we believe each event happens in time, but of what time consists, its properties and nature, we do not have any sufficient ground as a support for our claim. Furthermore, the debate has shown that for any meaningful and clearer progress to be

${ }^{13}$ Carr Herbert Wilson: Leibniz (New York, Dover Publication, Inc..1920) ng 163-164 
concepts have to be sufficiently understood. For instance, concepts such as space, causation, present, past, future, earlier than, later than, etc. All of these raise the problem of the relationship between our language (mathematical, logical, geometrical and grammatical languages inclusive) and the question of time on one hand and the relationship between our language and the supposed mental phenomena, on the other. There is the possibility of the fact that the problem is that of a certain technical or conceptual deficiency in our language.

Taye Richard Oyelakan is of the Department of Philosophy, Obafemi Awolowo University, Ile Ife, Nigeria.

\section{REFERENCES}

Broad C. D., Leibniz: An Introduction in C. Lewy (ed) (New York, Cambridge University Press, 1975)

Carr Herbert Wilson: Leibniz (New York, Dover Publication, Inc., 1920)

Findlay J. N.; Time: A Treatment of Some Puzzles Ed in J.J.C.Smart: Problems of Space and Time (New York, Macmillan Publishing Co., INC., New York, 1964)

Goodman Nelson; Time and Language, And the Passage of Time Ed in J.J.C.Smart: Problems of Space 
and Time (New York, Macmillan Publishing Co., INC., New York, 1964)

Hendel Charles Williams: Studies in the Philosophy of David Hume (Indianapolis, Ind., Bobbs-Merrill, 1963)

J.J.C.Smart: Problems of Space and Time (New York, Macmillan Publishing Co., INC., New York, 1964)

John Handyside: Kant Inaugural Dissertation and Early Writings on Space. (Chicago, Open Court Pub., 1929)

McTaggart J.ME: 'The Unreality of Time', in Le Poidevin, Robin, and McBeath, Murray (eds.), The Philosophy of Time. (Oxford University Press, 1993) This information is from the internet.

Quine W.V.; "Time" in J.J.C.Smart (ed), Problems of Space and Time (New York, Macmillan Publishing Co., INC., New York, 1964) 